\title{
Güven faktörü aracılık rolünün; lojistik, pazarlama ve üretim arasındaki içsel entegrasyon ile tedarik zinciri performansı arasındaki ilişkide incelenmesi
}

\begin{abstract}
An investigation of the mediating role of trust factor in the relationship between internal integration of logistics, marketing and production functions and supply chain performance
\end{abstract}

${ }^{1}$ Dr., Hacettepe Üniversitesi, Ankara,

Türkiye, zafersayan26@gmail.com

ORCID: 0000-0003-4372-057X

2 Doç. Dr., Hacettepe Üniversitesi, Ankara,

Türkiye, chatice@hacettepe.edu.tr

ORCID: 0000-0002-5927-1783

3 Dr. Öğr. Üyesi, Bingöl Üniversitesi, Bingöl, Türkiye, ekoc@bingol.edu.tr

ORCID: 0000-0002-8209-5714

Sorumlu Yazar/Corresponding Author:

Zafer Sayan,

Hacettepe Üniversitesi, Ankara, Türkiye,

zafersayan26@gmail.com

Başvuru/Submitted: 4/05/2021

Revizyon/Revised: 5/08/2021

Kabul/Accepted: 11/08/2021

Yayın/Online Published: 25/09/2021

Atıf/Citation: Sayan, Z. \& Çalıpınar, H., \& Koç, E., 48TGüven faktörü aracılık rolünün; lojistik, pazarlama ve üretim arasındaki içsel entegrasyon ile tedarik zinciri performansı arasındaki ilişkide incelenmesi, bmij (2021) 9 (3): 851-868, doi: https://doi.org/10.15295/bmij.v9i3.1830

\author{
Zafer Sayan $^{1}$ \\ Hatice Çalıpınar ${ }^{2}$ \\ Erdinç Koç3
}

\section{Öz}

Tedarik zincirinin etkin yönetilmesi işletmelerin faaliyetlerinin sürdürebilmesi açısından önemli bir rol oynamaktadır. Bu nedenle tedarik zinciri performansının belirlenebilmesi için tedarik zinciri entegrasyonu ve boyutlarından biri olan içsel entegrasyonun birlikte değerlendirilmesi önem kazanmaktadır. Bu çalışmanın amacı, işletme içi ortak sorumluluk alanları bulunan lojistik, pazarlama ve üretim arasındaki içsel entegrasyon ile tedarik zinciri performansı arasındaki ilişkide güven faktörü aracılık rolünün incelenmesi ve öneminin belirlenmesidir. Bu amaçla imalat sektöründe Ankara ve İstanbul'da faaliyette bulunan orta ve büyük ölçekli işletmeler üzerinde ampirik bir çalışma yapılmıştır. Oluşturulan teorik model, güvenirlik ve geçerlik testlerine tabi tutulduktan sonra bootstrap yöntemi ile analiz edilmiştir. Araştırma sonuçlarına göre; güvenin aracı değişken olarak kullanılması lojistik, pazarlama ve üretim arasındaki içsel entegrasyonun, tedarik zincirinin süre odaklı performansına anlamlı ve olumlu yönde etki ettiği tespit edilmiştir. Yapılan bu çalışma, araştırmacılara tedarik zinciri yönetimi çalışmalarında içsel entegrasyon ve tedarik zinciri performansı ilişkisinin güven aracı değişkeni ile olan bağlantısını göstermesi açısından önemlidir.

Anahtar Kelimeler: Tedarik Zinciri Performansı, Lojistik, Pazarlama, Üretim, İçsel Entegrasyon, Güven

Jel Kodlari: M11, L14, M31

\begin{abstract}
Effective management of the supply chain plays an essential role in the sustainability of businesses activities. For this reason, to determine the supply chain's performance, it is essential to evaluate the supply chain integration together with the internal integration, which is a dimension of it. The purpose of this study is to examine and to determine the importance of the mediating role of the trust factor in the relationship between the internal integration between logistics, marketing and production and supply chain performance, which have common areas of responsibility within the enterprise. For this purpose, an empirical study has been conducted on medium and large scale enterprises operating in the manufacturing sector in Ankara and Istanbul. The theoretical model created was analyzed with the bootstrap method after being subjected to reliability and validity tests. According to the research results, it has been determined that the use of trust as a mediating variable has a significant and positive effect on the internal integration between logistics, marketing and production on the time-oriented performance of the supply chain. Therefore, this study is vital in showing the relationship between internal integration and supply chain performance in supply chain management studies, with trust as a mediating variable.
\end{abstract}

Keywords: Supply Chain Performance, Logistics, Marketing, Production, Internal Integration, Trust

Jel Codes: M11, L14, M31 


\section{Extended Abstract}

An investigation of the mediating role of trust factor in the relationship between internal integration of logistics, marketing and production functions and supply chain performance

\section{Literature}

Research subject

Businesses have difficulty integrating their internal functions with their supply chain (SC) (Pagell, 2004). Internal integration often referred to as cross-functional integration, refers to the magnitude of interaction and communication, the level of information sharing, the degree of coordination, and the scope of joint participation between functions (Montoya-Weiss, Massey and Song, 2001). At this point, the purpose of internal integration is to ensure that departments and functions within an enterprise operate as a single integrated process (Flynn, Huo and Zhao, 2010). In order to achieve this, it is suggested that logistics is an exemplary interface to facilitate the internal integration of the business (Morash, Dröge and Vickery, 1996). In this context, logistics should work closely with production and marketing to plan, coordinate and integrate cross-functional activities to create value for customers within the business (Chen, Mattioda and Daugherty, 2007).

The literature on the evaluation of the performance of the SC in which businesses are involved includes a wide variety of studies, including the conceptual frameworks of measurement criteria (Gunasekaran, Patel and Tirtioglu, 2001). However, few studies on the concept of "measuring time", which is included in the classification of measurement criteria used in evaluating the SC performance, indicate that time-oriented strategies examine the performance results (Droge, Jayaram and Vickery, 2004). Therefore, within the scope of the relationship between SC integration and performance, besides examining the direct relationship, the effect of various factors in the mediating relationship was also investigated. In this context, in the study conducted by Tarifa-Fernandez and Burgos-Jimenez (2017), it was determined that ten different mediating variables were used in 17 studies on the relationship between internal integration and performance. Furthermore, in this study, the trust mediating variable was evaluated for the first time in the relationship between internal integration and SC performance.

\section{Research purpose and importance}

The purpose of this study is to examine the mediating role of the trust factor in the relationship between the internal integration between logistics, marketing and production functions, which have common areas of responsibility within the enterprise, and SC performance.

\section{Contribution of the article to the literature}

A different perspective will be provided in understanding the relationship between internal integration and performance, contributing to the literature with few studies. In addition, the mediating role of the trust variable, which is considered to affect this relationship, will be explained with Bootstrap analysis.

\section{Design and method}

\section{Research type}

The survey method, one of the quantitative research methods, was used in this study.

\section{Research problems}

Does the level of internal integration between logistics, marketing, and production impact the SC performance? Does the level of internal integration between logistics, marketing and production affect the perception of SC's time-oriented performance through the trust mediating variable?

\section{Data collection method}

The survey method, one of the quantitative data collection methods, was used in the study. The target population of the research consists of 1963 medium and large-scale enterprises in the manufacturing sector in Ankara and Istanbul provinces. The size of the target population was determined as a result of the data obtained from the Ministry of Science, Industry and Technology. As a result, it was concluded that 321 questionnaires would be sufficient in the sample calculation performed at a $95 \%$ confidence level related to the study population. On the other hand, 402 participants were surveyed by telephone method.

\section{Quantitative/qualitative analysis}

In the study, frequency and reliability analyzes were performed first. Then, concurrent validity analysis was performed with exploratory and confirmative factor analysis within the scope of validity analysis. Finally, bootstrap analysis was applied to examine the mediating effect.

\section{Research model}

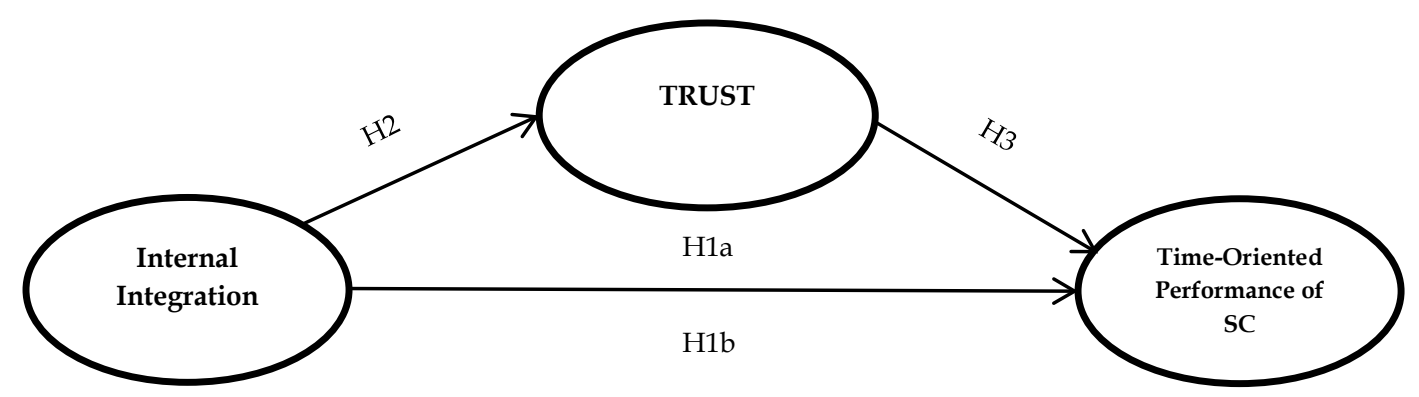




\section{Research hypotheses}

Hypothesis 1a: Internal integration has a significant and positive impact on the time-oriented performance of the supply chain.

Hypothesis 1b: Internal integration has a significant and positive effect on the time-oriented performance of the supply chain through the trust mediating variable.

Hypothesis 2: Internal integration has a significant and positive effect on the trust factor.

Hypothesis 3: The trust factor has a significant and positive effect on the time-oriented performance of the supply chain.

\section{Findings and discussion}

\section{Findings as a result of analysis}

The fact that the values obtained for the scales are higher than 0,7 means that the scales are reliable. All of the internal integration, trust and performance scales have values above 0,7 . The 0,85 value obtained as a result of the KMO analysis performed to determine whether the adequacy of the sample was achieved indicates that the study has sample adequacy. In addition, the test result performed for the assumption of normality shows that all observed variables have values between -2 and +2 , showing that the studies have a normal distribution (Alkan and Erdem, 2020; 73). The average variance extracted (AVE) and composite reliability $(\mathrm{CR})$ values obtained by the measurement model were examined for concurrent validity. While the average variance extracted was desired to be above 0,5 , Fornell and Larcker $(1981 ; 46)$ stated that when the AVE value is below 0,5 , the CR above 0,6 is sufficient for concurrent validity. When the AVE and CR values of the internal integration, trust and performance scales are examined, it is seen that the structure has concurrent validity. CI values do not contain zero, and the pvalue is less than 0,05 indicates that the hypotheses are confirmed (Serinikli, 2020). When the results obtained are examined, it is seen that the H1a hypothesis, in which the direct effect is investigated, and the H1b hypothesis, where the indirect effect is investigated, are confirmed.

\section{Hypothesis test results}

Within the scope of the regression model, where internal integration is the independent variable, and the time-oriented performance of SC is the dependent variable, it is understood that the internal integration positively affects the time-oriented performance of SC with a coefficient of 0,278 , and this effect is significant at the $p<0.01$ level. Therefore, with the results obtained, the hypothesis "H1: Internal integration has a significant and positive effect on the perception of the time-oriented performance of SC" is accepted.

According to the regression model, in which internal integration is the independent variable and the trust dependent variable, it is understood that internal integration positively affects trust with a coefficient of 0,402 , and this effect is significant at the $p$ $<0.01$ level. Therefore, with the results obtained, the hypothesis "H2: Internal integration has a significant and positive effect on trust" is accepted.

Within the framework of the regression model, in which trust is the independent variable, and the time-oriented performance of SC is the dependent variable, it is understood that trust positively affects the time-oriented performance of SC with a coefficient of 0,481. Furthermore, this effect is significant at the $p<0.01$ level. Thus, with the results obtained, the hypothesis "H3: Trust has a significant and positive effect on the perception of time-oriented performance" is accepted.

It can be stated that all conditions are met to test the mediating effect related to the results mentioned above. In this context, it is seen that the effect of internal integration on the time-oriented performance of SC decreased from 0,278 to 0,133. Thus, according to the results, it is understood that the trust dimension plays a partial mediating role.

\section{Discussing the findings with the literature}

The effect of internal integration between logistics, marketing and production within the enterprise on SC performance has been determined in different studies (Won Lee, Kwon and Severance, 2007; Flynn et al., 2010). Within the scope of the study, the effect of internal integration on the time-oriented performance of SC has been examined for the first time, and this effect has been confirmed. Furthermore, although the effect of trust among external integration elements on SC performance was discussed in previous studies (Cai, Jun and Yang, 2010; Ramirez, Roman, Ramos and Patrucco, 2020), the effect of trust among internal integration elements on SC performance was examined for the first time in this study. In this way, the gap in the literature has been tried to be filled.

\section{Conclusion, recommendation and limitations}

\section{Results of the article}

Within the scope of the study, the hypothesis stating that internal integration will positively affect the time-oriented performance of SC has been tested and verified. The result is following the studies in which internal integration has positive effects on SC performance. In addition, the hypothesis that internal integration positively affects the trust dimension has been analyzed and verified. In addition, the hypothesis that the created trust dimension has positive effects on the time-oriented performance of SC has been tested and verified.

\section{Suggestions based on results}

Based on this study, it can be stated that the time-oriented performance of SCs can be increased if the business managers establish internal integration between departments today, where the intensity of competition is increasing in almost every sector. Especially considering the pandemic conditions, businesses will be able to respond to customer orders faster in this way. Contribution to the literature can be made by investigating the independent and mediating variables used in the study on different dependent variables. In addition, by adding different mediating or regulatory variables to the existing research model. Since the study is carried out on the primary universe of the manufacturing sector, different researches can also be carried out on the service sector.

\section{Limitations of the article}

The study was conducted only in Turkey due to time and cost limitations. In future studies, the factors affecting the timeoriented performance of the supply chain with different independent and intermediary variables can be investigated. 


\section{Giriş}

1980'li yıllardan beri tedarik zincirlerini yönetmek işletmelerin üzerinde önemle durması gereken konuların başında gelmektedir. Artan ürün çeşitliliği, kısalan ürün yaşam döngüleri, 1990'lı yıllarla hızlanan küreselleşme ile üretim merkezlerinin coğrafi olarak dağılımı, yaygınlaşan dış kaynak kullanımı ve sürekli gelişen bilgi teknoloji araçlarının rekabet şartlarını daha zor hale getirdiği su götürmez bir gerçektir. Bu zorlu şartlarda işletmelerin varlıklarını sürdürmesi ve ötesinde rekabette ön sıralarda olmaları tedarik zincirleri etkin bir şekilde yönetebilmelerine bağlıdır. Bu doğrultuda Phadnis ve Fine (2017, s. 2305), son 20 yıl içerisinde özellikle küreselleşme ve e-ticaretin de etkisiyle değişen şartların, işletmeleri strateji oluşturmak ve kaynak bulmak için yeni arayışlara yönlendirdiğini ifade etmektedir.

Ross (2011), işletmelerin önceki dönemlerde müşteri taleplerini görmezden gelerek, itme sistemi ile standardize edilmiş mal ve hizmet üretmeye odaklandığını belirtmiştir. 21'inci yüzyıla gelindiğinde ise değişen müşteri isteklerinin karşılanmasını önemseyen, esnek üretim sistemlerinden faydalanarak gelen taleplere cevap verebilen, çevik ve yalın üretim felsefelerini benimseyen tedarik zincirlerinin başarılı olacağını ifade etmiştir (Rimiene ve Benatoynte, 2013, s. 600). Son dönemde tedarik zincirlerinin önem kazanmasını sağlayan ana unsurlar; işletmelerin uygulamış oldukları dikey entegrasyon stratejileri, ulusal ve uluslararası düzeyde artan rekabet ve işletme içerisindeki bir ya da birkaç fonksiyonun performansının yükseltilmesinin işletmenin genel performansına etkisinin sınırlı düzeyde olacağının fark edilmesidir (Lummus ve Vokurka, 1999, s. 12).

İşletmeler içsel fonksiyonlarını, içinde bulundukları tedarik zincirleri ile entegre etme zorluğunu yaşamaktadır (Pagell, 2004, s. 459). Genellikle fonksiyonlar arası entegrasyon olarak da adlandırılan içsel entegrasyon, etkileşim ve iletişimin büyüklügüunü, bilgi paylaşım düzeyini, koordinasyon derecesini ve işlevler arasında ortak katılımın kapsamını ifade etmektedir (Montoya-Weiss, Massey ve Song, 2001). Bu noktada içsel entegrasyonun amacı, bir işletme içindeki departmanlar ve fonksiyonların tek bir bütünleşik süreç olarak çalışmasını sağlamaktır (Flynn, Huo ve Zhao, 2010, s. 60). İçsel olarak entegre olan işletmede, fonksiyonel departmanlar müşteri gereksinimlerini karşılamak için iş birliğine dayalı ve senkronize bir sürecin parçası olarak hareket etmektedir (Flynn ve diğerleri, 2010, s. 60; Stock, Greis ve Kasarda, 1998, s. 38). Dolayısıyla içsel entegrasyon, gerçek zamanlı veri ve bilgilerin işletme fonksiyonları arasında paylaşılmasını, fonksiyonlar arası iş birliğini ve lojistik faaliyetlerin diğer fonksiyonel alanlarla koordinasyonunu gerektirmektedir (Chen ve Paulraj, 2004, s. 142; Flynn ve diğerleri, 2010, s. 60; Frohlich ve Westbrook, 2001, s. 185). İşletmenin içsel entegrasyonunu kolaylaştırmak için lojistiğin ideal bir arayüz konumunda olduğu önerilmektedir (Morash, Dröge ve Vickery, 1996, s. 365). Bu kapsamda lojistik, işletme içinde müşteriler için değer yaratmak üzere fonksiyonlar arası faaliyetleri planlamak, koordine etmek ve entegre etmek için üretim ve pazarlamayla yakından çalışmalıdır (Chen, Mattioda ve Daugherty, 2007, s. 14).

İşletmelerin içinde bulundukları tedarik zincirinin performansının değerlendirilmesi konusu, stratejik hedeflerin başarılması için iş birliği içerisinde bulunan birçok paydaşı içermesi nedeniyle bir dereceye kadar karmaşık şekilde ele alınması gereken bir iştir. Bu tür performans değerlendirmeleri, tedarik zincirlerinin kurumsal başarının önemli bir faktörü olarak kabul edildiği durumlarda özellikle önemli hale gelmektedir (Estampe, Lamouri, Paris ve Brahim-Djelloul, 2013, s. 247). Bu kapsamda tedarik zinciri performans değerlendirmesine ilişkin literatür, ölçme kriterlerinin kavramsal çerçeveleri de dahil olmak üzere çok çeşitli çalışmaları içermektedir (Gunasekaran, Patel ve Tirtiroglu, 2001). İfade edilen tedarik zinciri performansının değerlendirilmesinde kullanılan ölçme kriterleri sınıflandırması içerisinde bulunan "süre ölçme" kavramına ilişkin az sayıda çalışmada süre odaklı stratejilerin uygulanmasının performans sonuçların incelediği belirtilmektedir (Droge, Jayaram ve Vickery, 2004, s. 558).

Tedarik zinciri entegrasyonu ile performans arasındaki ilişki kapsamında, direk ilişkinin incelenmesinin yanında aracılık ilişkisinde bulunan çeşitli faktörlerin etkisi de araştırılmıştır. Bu kapsamda Tarifa-Fernandez ve Burgos-Jimenez (2017, s. 1249) yaptıkları çalışmada, içsel entegrasyon ile performans arasındaki ilişkiye yönelik 17 çalışmada 10 farklı aracı değişkenin kullanıldığı belirlenmiştir. Bu çalışmada ise içsel entegrasyonun tedarik zinciri performansına etkisinde güven değişkeninin aracllık rolü ilk kez test edilmektedir.

Bu çalışmanın amacı, işletme içi ortak sorumluluk alanları bulunan lojistik, pazarlama ve üretim fonksiyonları arasındaki içsel entegrasyon ile tedarik zinciri performansı arasındaki ilişkide güven faktörü aracılık rolünün incelenmesi ve öneminin belirlenmesidir. Bu şekilde az sayıda çalışmanın bulunduğu literatüre katkı olarak, içsel entegrasyon ile performans arasındaki ilişkinin anlaşılmasında 
farklı bir bakış açısı sağlanacaktır. Bunun yanında bu ilişkiyi etkileyebileceği değerlendirilen güven aracı değişkeninin rolü Bootstrap analizi ile açıklanacaktır. Bu kapsamda çalışma şu şekilde düzenlenmiştir. İkinci bölümde araştırma ile ilgili temel kavramlar, literatürde yapılan çalışmalar, araştırma modeli ve hipotezler oluşturulmuştur. Üçüncü bölümde araştırma yöntemine ilişkin örneklem, veri toplama yöntemi ve araştırmada kullanılan ölçekler verilmiştir. Dördüncü bölümde araştırma modelinin analizi yapılmış, elde edilen bulgular belirtilmiştir. Sonuçta ise, bulguların kavramsal çerçeve kapsamında değerlendirilmesi yapılarak, sektörde bulunan paydaşlara önerilerde bulunulmuştur.

\section{Literatür taraması}

\section{Entegrasyon ve içsel entegrasyon kavramı}

Günümüzde farklı endüstriyel sektörlerde faaliyette bulunan işletmeler, sadece sahip oldukları fonksiyonlarını ve altyapılarını, belirledikleri işletme stratejilerine bağlı olarak optimize etmek yerine, söz konusu iç süreçlerini içinde bulundukları tedarik zincirindeki tedarikçiler ve müşterilerle bağlantılı duruma getirmeye çalışmaktadır (Frohlich ve Westbrook, 2001, s. 185). Bu durumda önem kazanan tedarik zinciri entegrasyonu kavramının kapsamı, akademisyenler tarafından farklı şekilde değerlendirilmektedir. Bazı yazarlar tedarik zinciri entegrasyonunun, materyallerin ve parçaların akışına önem verdiğini belirtirken, bazıları ise bilgi, kaynak ve nakit akışını odak noktasına almaktadır (Flynn ve diğerleri, 2010, s. 59).

Tedarik zinciri entegrasyonunun, işletme açısından hem iç hem de dış unsurlarını içerdiğinden hareketle (Alfalla-Luque, Medina-Lopez ve Dey, 2013, s. 801; Chen, Daugherty ve Landry, 2009, s. 28), işletme içindeki içsel entegrasyon çalışanlar, fonksiyonlar ve departmanlar arasındaki iş birliğini ifade ediyorken, işletmeler arası dişsal entegrasyon ise gerek yukarı gerekse aşağı yönlü olmak üzere tedarik zinciri üyeleriyle olan iş birliğini belirtmektedir (Gomes, de Weerd-Nederhof, Pearson ve Cunha, 2003, s. 186).

İşletmelerin özelliklerini geliştirmelerinde önemli bir yaklaşım olarak belirtilen (Swink, Narasimhan ve Wang, 2007, s. 150; Zhao, Huo, Selen ve Yeung, 2011, s. 19) ve tedarik zinciri entegrasyonunun boyutlarından birisi olan içsel entegrasyonun, literatürde kapsadığı kavramlar açısından farklı tanımlamaları yapıldığından, bu kullanımların sunulduğu literatür araştırması Tablo 1'dedir.

Tablo 1: İçsel Entegrasyonun Kullanımındaki Farklılıklar

\begin{tabular}{|c|c|c|}
\hline \multicolumn{3}{|c|}{ İÇSEL ENTEGRASYON } \\
\hline Kaynak & Çalışma Alanı & Tanım \\
\hline Fawcett ve Closs (1993) & Lojistik ve imalat & Koordinasyon ve etkileşim \\
\hline $\begin{array}{l}\text { Kahn ve Mentzer (1996); Kahn ve McDonough (1997); } \\
\text { Kahn ve Mentzer (1998) }\end{array}$ & Pazarlama, diğer departmanlar & Etkileşim ve iş birliği \\
\hline $\begin{array}{l}\text { Stank, Daugherty ve Ellinger (1999); Ellinger (2000); } \\
\text { Ellinger, Keller ve Hansen (2006); Turkulainen ve } \\
\text { Ketokivi (2012); Jacobs, Yu ve Chavez (2016); Cheng, } \\
\text { Farooq ve Jajja (2020) }\end{array}$ & Lojistik, pazarlama ve imalat & İş birliği \\
\hline Stock, Greis ve Kasarda (2000) & Lojistik & Etkileşim, koordinasyon ve iletişim \\
\hline Verma, Thompson, Moore ve Louviere (2001) & İşlem yönetimi ve pazarlama & Birlikte çalışma \\
\hline $\begin{array}{l}\text { Narasimhan ve Kim (2001); Schramm-Klein ve } \\
\text { Morschett (2006) }\end{array}$ & Tz, lojistik ve pazarlama & Koordinasyon \\
\hline O’Leary-Kelly ve Flores (2002); Paiva (2010) & İmalat ve pazarlama & Koordinasyon, etkileşim ve iş birliği \\
\hline $\begin{array}{l}\text { Chen ve diğerleri (2007); Daugherty, Chen, Mattioda } \\
\text { ve Grawe (2009) }\end{array}$ & Lojistik ve pazarlama & Etkileşim ve iş birliği \\
\hline $\begin{array}{l}\text { Springinklee ve Wallenburg (2012); Freijele, Calle ve } \\
\text { Ugarte (2020) }\end{array}$ & Lojistik, üretim ve imalat & $\begin{array}{l}\text { Koordinasyon, dayanışma ve } \\
\text { uyumlu olma }\end{array}$ \\
\hline Wong, Wong ve Boon-itt (2013) & Üretim & $\begin{array}{l}\text { Etkileşim, bilgi paylaşım, } \\
\text { koordinasyon ve iş birliği }\end{array}$ \\
\hline Makepeace, Tatham ve Wu (2017) & Lojistik & İş birliği ve koordinasyon \\
\hline
\end{tabular}

Kaynak: Yazar tarafından üretilmiştir. 
Tedarik zinciri entegrasyonunun alt boyutu durumundaki içsel entegrasyona yönelik, içerdiği kavramlar açısından araştırmacılar tarafından ortak bir tanımlama yapılamamaktadır. Bu durum, içsel entegrasyonun araştırılmaya değer bir konu olarak araştırmacıların çeşitli çalışmalar yürüttüğü bir alan olmasını sağlamaktadır.

\section{Tedarik zinciri ve içsel entegrasyon}

Tedarik zincirinin bir kavram olarak ilk defa kullanıldığı 1980'lerden beri tedarik zinciri ile ilgili olduğu düşünülen temel işletme fonksiyonlarının hangileri olduğu konusunda bir fikir birliği henüz sağlanmamıştır (Zacharia, Sanders ve Fugate, 2014, s. 73). Brewer ve Speh (2000, s. 77), tedarik zinciri içerisinde gerçekleştirilen fonksiyonları üretim planlaması, kaynak bulma, envanter yönetimi, satın alma, imalat, müşteri hizmeti, sipariş süreci ve depolama olarak ifade etmektedir. Farklı bir çalışmada ise Tan (2001, s. 41), tedarik zincirinin kavramsal çerçevesinin iki farklı yoldan gelişim kat ettiğini ifade etmiş, bu yolların ise tedarik faaliyetleri ve satın alma ile lojistik ve taşımacılık olduğunu ortaya koymuştur.

Chen ve Paulraj (2004, s. 132), tedarik zinciri yazının hızlı bir şekilde gelişmesine katkıda bulunan alanları; lojistik ve taşıma, satın alma ve tedarik, pazarlama, ağ örgüsü, organizasyonel davranış, stratejik yönetim, operasyonel yönetim ve yönetim bilgi sistemleri olarak sıralanmaktadır. Burgess, Singh ve Koroglu (2006, s. 716), yapmış oldukları çalışma ile ulaştığı ampirik bulgular neticesinde tedarik zincirinin temel fonksiyonlarının operasyonel yönetim, satın alma ve lojistik olduğunu ifade etmiştir. Frankel, Bolumole, Eltantawy, Paulraj ve Gundlach $(2008$, s. 3), tedarik zincirinin temel fonksiyonlarını; lojistik, operasyon yönetimi, satın alma ve pazarlama olarak belirtmiştir. Kanda ve Deskmuh $(2008$, s. 322) ise, tedarik zinciri sürecini oluşturan faaliyetler olarak üretim, tedarik ve dağıtımı belirtmektedir.

Farklı yazarlara göre tedarik zincirini oluşturan temel fonksiyonlar ayrışmaktadır. Bu çalışma kapsamında tedarik zincirinin çeşitli fonksiyonlarından üretim, lojistik ve pazarlamanın seçilmesinin nedeni, bu fonksiyonların örtüşen faaliyetlerinin bulunması ve birbirleri ile bağlantılı şekilde operasyonlar gerçekleştiren fonksiyonlar olmasıdır. Lojistik ve üretim fonksiyonlarının örtüşen faaliyetleri; fabrika yeri seçimi, üretim planlama ve satı alma faaliyetleridir. Pazarlama ve lojistik arasındaki örtüşen faaliyetler ise; müşteri hizmeti, perakendeci yeri seçimi, paketleme, bilgi akışı, dağıtım kanalları ve fiyatlandırma faaliyetleridir (Ballou, 2004, s. 26). Bu kapsamda üretim, lojistik ve pazarlama fonksiyonları arasındaki iş birliği seviyesinin yüksekliği, içsel entegrasyonun gerçekleştirilmesine katkı sağlayarak tedarik zinciri performansının artırılmasına etkide bulunabilecektir.

\section{Tedarik zinciri performansının süre odaklı değerlendirilmesi}

Rekabetin küresel boyuta taşındığı günümüzde tedarik zincirlerinin hedefleri bu zincirler içerisinde yer alan işletmelerin ortak hedefleri olarak kabul edilmektedir. Maliyetlerin azaltılması, kalitenin yükseltilmesi ve sipariş teslim karşılama süresinin kısaltılması imalat ya da hizmet üreten işletmenin yalnız başına üstesinden geleceği zorluklar değildir. İşletmeler içerisinde bulunduğu tedarik zinciri üyeleri ile iş birliği geliştirerek müşteri gereksinimlerini karşılayabilir. Tedarik zincirinin dış paydaşları ile olduğu gibi iç paydaşları ile de kurulan etkin iletişim ağı tedarik zinciri performansına etki ederek artı değer oluşumuna katkı sağlayacaktır. Bu noktada, kurulan etkin iletişim ağının tedarik zincirinin dış ve iç paydaşları arasındaki operasyonların sürelerine etkisi ön plana çıkmaktadır.

Daugherty ve Pittman (1995, s. 55), hazırlık sürelerinin etkin bir şekilde kullanılması sayesinde döngü sürelerinin kısalacağını ve bu durumun işletmelerin zamanı daha verimli kullanmalarını sağlayacağını ifade etmektedir. İşletmeler imalat ve teslimat hazırlık süreleri ile ilgilenirken, müşteriler sipariş verme ve ürünü teslimi alma arasında geçen süreye odaklanmaktadır. Benzer şekilde Bower ve Hout (1988, s. 111) ile Tersine ve Hummingbird (1995, s. 17), üretim öncesi, üretim aşamasında ve üretim sonrasındaki faaliyetlerde ortaya çıkan hazırlık sürelerinin azaltılmasının, işletmeye sağladığı avantajlara vurgu yapmaktadır.

Hazırlık sürelerinin azaltılması son yıllarda tedarik zinciri yönetiminde üzerinde çok sayıda çalışma yapılan alanlardan olan tedarik zinciri çevikliği ile ilişkilendirilebilir. Acar ve Uzunlar (2014, s. 746) tarafından esneklik ve süreler ile ilişkili hız unsurlarını içerdiği belirtilen çeviklik kavramı kapsamında, tedarik zinciri çevikliğinin sağlanması adına, hazırlık sürelerinin azaltılması amacıyla BT araçlarının kullanılabileceği ileri sürülmektedir. Tedarik zinciri içerisinde BT kullanımı sayesinde bilgi akışının kolaylaşması ile birlikte operasyonel esneklik artmakta, pazar değişikliklerine karşı duyarlılık yükselmektedir (Li, Chow, Choi ve Chan, 2016, s. 58). 
Malzeme akışı ve envanter yönetimi boyunca gerçek zamanlı bilgi paylaşımı, üretim planlamasını kolaylaştırmakta, lojistik faaliyetlerin kontrolünü gerçekleştirerek teslim süresinin kısalmasını sağlamaktadır (Ye ve Wang, 2013, s. 372). Tedarik zinciri performansı üzerine yapılan literatür taraması sonucunda çeşitli sınıflandırmalar ile farklı performans kriterlerinin çalışmalarda kullanıldığı görülmektedir. Süre odaklı performans kriterine sahip çalışma ise sınırlı sayıdadır. Belirtilen az sayıda çalışma süre odaklı performans kriteri kapsamında yeni ürün geliştirme süresi ve sipariş karşılama süresine odaklanmaktadır. Bu kapsamda Droge ve diğerleri (2004), ürün geliştirme süresi, ürün döngü süresi ve cevap vermeyi süre odaklı performans kriterleri olarak belirlemiştir. Jayaram ve diğerleri (2000) ile Perçin (2005), söz konusu kriterler anlamında müşterilere cevap verme süresi, yeni ürün geliştirme süresi, sipariş karşılama süresi ve teslimat hızını tespit etmiştir. Acar ve Uzunlar (2014) ise, süre odaklı performans kriterleri olarak, sipariş karşılama performansı, yeni ürün geliştirme performansı, teslimat hızı, müşteriye sunulan ürün ya da hizmetin performansını kullanmıştır.

İçsel entegrasyon ile performans arasındaki ilişki kapsamında Germain ve Iyer (2006), Flynn ve diğerleri (2010), Jayaram ve Xu (2013), Maiga, Nilsson ve Ax (2015), Liu ve Jayaram (2019), Shah ve Sohomro (2020) tarafından araştırma gerçekleştirilmiş ve bu çalışmalarda içsel entegrasyonun, performans üzerindeki anlaml etkisi tespit edilmiştir. Yine içsel entegrasyonun, tedarik zinciri performansina olan etkisi Abdallah, Obeidat ve Aqqad (2014), Shee, Miah, Fairfield ve Pujawan (2018), Peng, Shen, Liao ve Wang (2020) tarafından araştırılmış ve anlamlı etki ortaya koyulmuştur. Bunlarla birlikte içsel entegrasyon ile tedarik zincirinin süre odaklı performansı arasındaki ilişkiyi ortaya koyan bir çalışmaya literatürde rastlanılmamıştır. Mevcut literatür ve yapılan araştırmalar doğrultusunda test edilmek üzere aşağıdaki hipotez geliştirilmiştir:

Hipotez 1a: İçsel entegrasyonun tedarik zincirinin süre odaklı performansı üzerinde anlamlı ve olumlu yönde bir etkisi bulunmaktadır.

\section{Güven kavramı ve aracı değişken rolü}

Güven, itimat duyulabilen bir paydaşa inanma konusunda gösterilen isteklilik durumudur. Moorman, Zaltman ve Deshpande (1992, s. 315) ise güven kavramını iki farklı şekilde ifade etmiştir. İlkinde güveni, ilişki kalitesinin bir niteliği olarak ifade ederken ikincisinde ilişki kalitesinin kimlikleyici unsuru olarak belirtmiştir. Güven kavramını benzer şekilde ifade eden Morgan ve Hunt (1994, s. 23), Moorman ve diğerleri (1992)'den ayrıldıkları noktayı davranışsal niyet kapsamında istek duyma olarak belirtmiştir. Güven kavramını belirten veya öncülü konumundaki faktörleri ise şu şekilde sıralamaktadır: ilişkiyi bitirme maliyeti, ilişkinin yararları, tarafların paylaştığı değerler, resmi veya gayri resmi şekilde doğru zamanda bilgi paylaşımını ifade eden iletişim kavramı, fayda bekleyen davranış. Morgan ve Hunt (1994, s. 22), taraflar arasında güvenin olup olmadığının sonucu olarak şu durumların gelişebileceğini belirtmiştir: kabul etme ve ilişkiyi bitirme eğilimi, karşılıklı amaçlara ulaşma noktasında tarafların birlikte çalışmasını ifade eden iş birliğini, ilişkide meydana gelebilecek fonksiyonel uyuşmazlıklar, karar vermede yaşanacak belirsizlik durumu.

Şengün (2007, s. 11), işletmeler açısından güvenin kişiler arası ve işletmeler arası olmak üzere iki farklı şekilde değerlendirilebileceğini ifade etmiştir. İşletmeler arasında güvenin oluşmasının arka planında kişiler arasında oluşan güvenin işletme boyutuna taşınıp taşınmadığı yatmaktadır. İşletmeler arasında oluşan güven kişiler arasında tesis edilen güvenden daha fazla zarar verici olabilir çünkü işletmeler arasında oluşan güven işletme varlıklarının riske atılmasına neden olabilir. Cengiz ve Aksoy (2017, s. 6) ise, tedarik zincirlerinde yer alan tedarikçi ve müşterilerle ortak amaçlar doğrultusunda iş birliği geliştiren işletmelerin bu sayede hızlı bir şekilde değişen rekabet ortamına adapte olmaya çalıştığını ifade etmiştir. Tedarik zinciri üyeleri arasında iş birliği oluşturmanın ve kurulan iş birliğinin sürekliliğinin sağlanmasında ana unsur ise güvendir. Güvenin tedarik zinciri üyeleri arasında oluşturulması ile üyeler için daha iyi bir çalışma çevresi oluşturulabilir, riskler ve belirsizlikler azaltılabilir, üyeler arasında yapılan kontratların güvenilirliği ve iş birliğinin faydaları artırılabilir. Dolayısıyla, tedarik zincirinin davranışsal boyutlarından olan güvenin tedarik zinciri performansını olumlu yönde etkilediği anlaşılmaktadır (Wu, Chuang ve Hsu, 2014, s. 124).

Literatürdeki çalışmalarda tedarik zinciri entegrasyonu ile tedarik zinciri performansı arasındaki ilişkide aracı değişkenleri inceleyen Tarifa-Fernandez ve Burgos-Jimenez (2017, s. 1249) 27 farklı değişkenin kullanıldığını ifade etmektedir. Ayrıca, bu çalışmanın da konusu olan güven kavramının ise tedarikçi entegrasyonu kapsamında sadece bir çalışmada aracı değişken olarak kullanıldığı belirtilmektedir. Tedarik zincirinin diş entegrasyon boyutunda güven kavramının farklı ilişkilere etkisini inceleyen az sayıda da olsa çalışma bulunmasına rağmen güven kavramının içsel entegrasyonla ilişkisini inceleyen bir çalışmaya rastlanılmamıştır. İşletme içerisindeki departmanların farklı hedefleri bulunabilir ancak bu hedefler işletme stratejisi ile uyumlu olmalıdır. Departmanlar arası kurulan iş birliği ile departmanların aslında çatışma içerisinde olmadığı ve işletme stratejisine 
uygun hareket etmek zorunda olduğu anlaşılacaktır. Kurulan içsel entegrasyon departmanlar arasında güvenin oluşmasını sağlayarak işletmenin amaçlarına ulaşmasına katkı sağlayacaktır. Bu doğrultuda çalışmada içsel entegrasyonun güven aracı değişkeni üzerinden tedarik zinciri performansına etkisi aşağıda oluşturulan hipotez ile incelenmek istenmektedir. Elde edilen bulgular ile bu ilişkinin test edilmesinin literatüre katkı sağlayacağı düşünülmektedir.

Hipotez 1b: İçsel entegrasyonun tedarik zincirinin süre odaklı performansı üzerinde güven faktörü üzerinden anlamlı ve olumlu bir etkisi bulunmaktadır.

Entegrasyon, işletme içerisindeki departmanlar arasında mevcut ya da kurulacak olan etkileşim ve iş birliği olarak tanımlanabilir. Etkileşimle kastedilen iletişim araçlarının etkin kullanılarak departmanlar arasında bilgi paylaşımının sağlanması iken, iş birliği departmanların istekli bir şekilde aynı hedefler doğrultusunda birlikte çalışabilmelerini ifade etmektedir (Kahn ve Mentzer, 1996, s. 9). İşletme içerisinde oluşturulan içsel entegrasyon departmanlar arasında iletişim, etkileşim ve iş birliğinin artmasına olanak sağlayacaktır. Departmanlar arasında oluşan entegrasyonun bu sayede birlikte çalışma ortamına katkı sağlayacağı ve departmanlar arasında güvenin oluşmasına ya da artmasına olumlu yönde etki edeceği düşünülmektedir. Bunun yanında, yardımseverlik ve iyi niyet göstergesi olan güven (McAllister, 1995, s. 25), çalışanlar arasında yakın ilişki ve güvenilirliği tesis etmenin yanı sıra, fonksiyonlar arası koordinasyona yönelik katı gözlem ve kontrol sistemlerine bağımlılık ile fırsatçılığı azaltmaktadır (Zaheer, McEvily ve Perrone, 1998, s. 142; Bunduchi, 2013, s. 147). Mevcut literatür ve yapılan araştırmalar doğrultusunda test edilmek üzere aşağıdaki hipotez geliştirilmiştir:

Hipotez 2: İçsel entegrasyonun güven faktörü üzerinde anlamlı ve olumlu yönde bir etkisi bulunmaktadır.

McAllister (1995, s. 25) güven kavramını, bir tarafın, diğer tarafa ait sözler, faaliyetler ve kararlar temelinde hareket etme isteği ile kendinden emin olma durumu olarak tanımlamaktadır. Bu kavramın taşıması gereken bileşenler olarak ise, inanç ve davranışsal niyet belirtilmektedir (Moorman ve diğerleri, 1992, s. 315). Güven, tedarik zincirleri içerisinde iş birliğini etkileyen en önemli faktörlerden birisi olarak görülmektedir (Kelle ve Akbulut, 2005, s. 48). Güven kavramına organizasyonel seviyede bakıldığında, paydaşlar arasındaki ilişkinin başarısında en dikkat çekici unsurdur (Jeffries ve Reed, 2000, s. 875). Tedarik zinciri üyeleri arasında oluşturulan güven, işletmelerin çalışma çevresinin birlikte çalışmaya daha uygun hale gelmesine, yapılan antlaşmaların güvenilirliğinin artmasına, risklerin ve belirsizliklerin azaltılmasına etki etmektedir (Wu ve diğerleri, 2014, s. 124). Bu doğrultuda güven aracı değişkeninin tedarik zincirinin süre odaklı performansı üzerinde olumlu yönde etkisi olduğu değerlendirilmektedir. Mevcut literatür ve yapılan araştırmalar doğrultusunda test edilmek üzere aşağıdaki hipotez geliştirilmiştir:

Hipotez 3: Güven faktörünün, tedarik zincirinin süre odaklı performansı üzerinde anlamlı ve olumlu yönde bir etkisi bulunmaktadır.

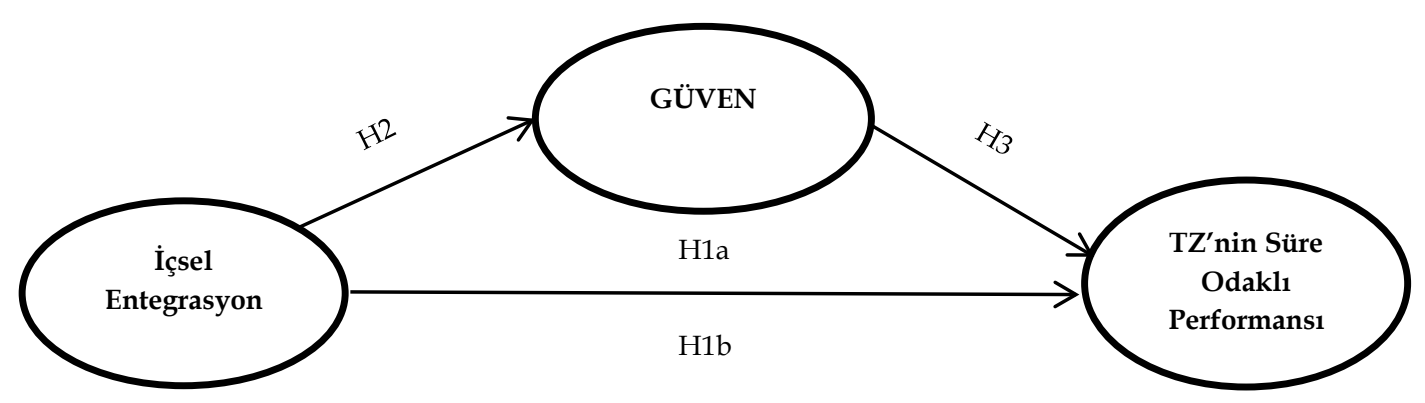

\section{Şekil 2: Araştırmanın Modeli}

Kaynak: Yazar tarafından üretilmiştir.

Araştırma modeli, Gimenez ve Ventura'nın (2005, s. 25) içsel entegrasyon ile performans arasındaki ilişki temel alınarak geliştirilmiştir. Yapılan çalışmadan farklı olarak bu çalışmada tedarik zincirinin süre odaklı performansı incelenmektedir. Bununla birlikte içsel entegrasyon ile tedarik zincirinin süre odaklı performansı arasındaki ilişkide güven aracı değişkeninin rolü literatürde ilk defa test edilmektedir. Bu doğrultuda oluşturulan model Şekil 2'de görülmektedir. 


\section{Yöntem}

Araştırmada nicel veri toplama yöntemlerinden olan anket yöntemi kullanılmıştır. Araştırmanın çalışma evrenini Ankara ve İstanbul illerinde imalat sektöründeki 1963 orta ve büyük ölçekli işletme oluşturmaktadır. Çalışma evreni büyüklüğü Bilim, Sanayi ve Teknoloji Bakanlığı'ndan alınan veri neticesinde belirlenmiştir. Çalışma evreni dikkate alınarak \%95 güven seviyesinde gerçekleştirilen örneklem hesaplamasında 321 anketin yeterli olacağı sonucuna ulaşılmıştır. Buna karşın 402 katılımcıya telefon yöntemi ile anket yapılmıştır. Anket formu iki bölümden oluşmaktadır. Oluşturulan anket formunun ilk bölümü katılımcılara ve çalıştıkları işletmelere ilişkin tanımlayıcı bilgileri öğrenmeyi amaçlayan altı sorudan oluşmakta iken ikinci bölüm 14 önermeden oluşmaktadır. İkinci bölüm "hiç katılmıyorum" ile "kesinlikle katılıyorum" arasındaki aralığa sahip 5'li likert tipi önermelerden meydana gelmektedir. Araştırmada üç farklı yazardan alınan üç ayrı ölçekten yararlanılmıştır. Lojistik, pazarlama ve üretim arasındaki içsel entegrasyonu ölçmeye yönelik yedi maddelik ölçek Gimenez ve Ventura $(2005$, s. 27)'nın, tedarik zincirinin süre odaklı performansını ölçmeye yönelik dört maddelik ölçek Acar ve Uzunlar (2014, s. 749)'ın ve güven boyutunu ölçmeye yönelik dört maddelik ölçek ise Garcia, Sanzo ve Trespalacios (2008, s. 723)'un çalışmalarından faydalanılarak oluşturulmuştur.

\section{Bulgular}

\section{Tanımlayıcı istatistikler}

Katılımcılara yöneltilen altı tanımlayıcı soru ile kendilerine ve çalıştıkları işletmelere ilişkin tanımlayıcı verilere ulaşılmaya çalışılmıştır. Araştırma konusu dikkate alınarak çalışmaya katılacakların belirli pozisyonlara sahip olması ön şart olarak kabul edilmiştir. Bu doğrultuda ankete katılan katılımcıların 132'si $(\% 32,8)$ işletme içerisinde üretim müdürü, $144^{\prime}$ ü $(\% 35,8)$ pazarlama müdürü, 80'i $(\% 19,9)$ lojistik müdürü ve $46^{\prime}$ s1 $(11,4)$ ise tedarik zinciri müdürü pozisyonunda çalıştığını ifade etmiştir. Ayrıca katılımcıların 315'i $(\% 78,4)$ çalıştıkları işletmenin orta ölçekli ve 87'si $(\% 21,6)$ çalıştıkları işletmenin ise büyük ölçekli işletme olduğunu belirtmiştir. Katılımcılara sorulan diğer tanımlayıcı sorulara verilen cevaplara ilişkin istatistiki bilgiler Tablo 2' de yer almaktadır.

Tablo 2: Katılımcıların Tanımlayıcı İstatistikleri

\begin{tabular}{|c|c|c|c|c|c|c|c|}
\hline \multicolumn{2}{|l|}{ Tanımlayıcı Sorular } & \multirow{2}{*}{$\begin{array}{l}\text { Frekans } \\
364\end{array}$} & \multirow{2}{*}{\begin{tabular}{|l}
$\begin{array}{l}\text { Yüzde } \\
\text { (\%) }\end{array}$ \\
90.5
\end{tabular}} & \multicolumn{2}{|c|}{ Tanımlayıcı Sorular } & \multirow{2}{*}{$\begin{array}{l}\text { Frekans } \\
117\end{array}$} & \multirow{2}{*}{$\begin{array}{l}\begin{array}{l}\text { Yüzde } \\
\text { (\%) }\end{array} \\
29.1\end{array}$} \\
\hline \multirow{3}{*}{$\begin{array}{l}\text { İşletmenin Sermaye } \\
\text { Yapısı }\end{array}$} & Tamamen Yerli & & & \multirow{4}{*}{$\begin{array}{l}\text { Pozisyonda } \\
\text { Bulunma } \\
\text { Süresi }\end{array}$} & $1-3$ yil & & \\
\hline & Yabancı Ortaklı & 24 & 6 & & $4-6$ y1l & 91 & 22.6 \\
\hline & Tamamen Yabancı & 14 & 3.5 & & 7-12 yıl & 102 & 25.4 \\
\hline \multirow{3}{*}{ İşletmenin Pazarları } & Sadece Yurt İçi & 78 & 19.4 & & 12 y1l üzeri & 92 & 22.9 \\
\hline & Sadece Yurt Dışı & 28 & 7 & \multirow{2}{*}{ Çalışan Sayısı } & 50-249 kişi & 315 & 78.4 \\
\hline & Her İki Pazar & 296 & 73.6 & & $\begin{array}{l}250 \text { kişi ve } \\
\text { üzeri }\end{array}$ & 87 & 21.6 \\
\hline \multirow{4}{*}{ Pozisyon } & Üretim Müdürü & 132 & 32.8 & \multirow{4}{*}{$\begin{array}{l}\text { İşletmenin } \\
\text { Faaliyet Y1lı }\end{array}$} & $0-10$ yıl & 30 & 7.5 \\
\hline & $\begin{array}{l}\text { Pazarlama } \\
\text { Müdürü }\end{array}$ & 144 & 35.8 & & $11-20$ y1l & 111 & 27.6 \\
\hline & Lojistik Müdürü & 80 & 19.9 & & $21-30$ y1l & 102 & 25.4 \\
\hline & TZ Müdürü & 46 & 11.4 & & $\begin{array}{l}31 \text { y1l ve } \\
\text { üzeri }\end{array}$ & 159 & 39.6 \\
\hline
\end{tabular}

\section{Güvenirlik ve geçerlik analizi}

Elde edilen veriler öncelikle güvenirlik analizine tabi tutulmuştur. Bu kapsamda içsel entegrasyon, güven ve performans alt boyutlarına ilişkin iç tutarlılık Cronbach Alpha katsayıları hesaplanmıştır. Ölçeklere ilişkin elde edilen değerlerin $0,7^{\prime}$ den yüksek olması ölçeklerin güvenilir olduğunu ifade etmektedir. Tablo 3'de görüldüğü üzere içsel entegrasyon, güven ve performans ölçeklerinin tümü 0,7'nin üstünde değerlere sahiptir. Çalışmada yapı geçerliliğinin test edilmesi amaçyla ilk aşamada açımlayıcı faktör analizi, ikinci aşamada ise doğrulayıcı faktör analizi yapılmıştır. Açımlayıcı faktör analizi sonucunda oluşan faktörler ve bu faktörlere ilişkin maddeler Tablo 3'de görülmektedir. Faktör analizinde $0,30^{\prime}$ un altında faktör yüküne sahip maddelerin analizden çıkartılması önerilmektedir (Can, 2014, s. 332). Bu kapsamda IC1 ve IC3 maddeleri analizden çıkartılarak açıklayıcı faktör analizi sonucunda elde edilen değerler Tablo 3 'de gösterilmektedir. Örneklem yeterliliğinin sağlanıp 
sağlanmadığının tespiti için gerçekleştirilen KMO analizi sonucunda elde edilen 0,85 değeri çalışmanın örneklem yeterliliğine sahip olduğunu ifade etmektedir. Ayrıca normallik varsayımı için gerçekleştirilen test sonucu tüm gözlenen değişkenlerin -2 ile +2 arasında değerler alması çalışmaların normal dağılıma sahip olduğunu göstermektedir (Alkan ve Erdem, 2020, s. 73).

Tablo 3: Güvenirlik ve Açımlayıcı Faktör Analizi Sonuçları

\begin{tabular}{|c|c|c|c|c|}
\hline Faktörler ve Maddeler & Faktör Yükü & Chronbach Alpha & KMO & Açıklanan Varyans \\
\hline \multicolumn{3}{|l|}{ İçsel Entegrasyon } & \multirow{16}{*}{0,85} & \multirow{16}{*}{0,58} \\
\hline IE2 & 0,38 & & & \\
\hline IE4 & 0,66 & & & \\
\hline IE5 & 0,76 & 0,13 & & \\
\hline IE6 & 0,75 & & & \\
\hline IE7 & 0,74 & & & \\
\hline \multicolumn{3}{|l|}{ Güven } & & \\
\hline G1 & 0,70 & \multirow{4}{*}{0,83} & & \\
\hline G2 & 0,80 & & & \\
\hline G3 & 0,80 & & & \\
\hline G4 & 0,77 & & & \\
\hline \multicolumn{3}{|l|}{ Performans } & & \\
\hline P1 & 0,75 & \multirow{4}{*}{0,77} & & \\
\hline P2 & 0,80 & & & \\
\hline P3 & 0,70 & & & \\
\hline P4 & 0,71 & & & \\
\hline
\end{tabular}

Açıklayıcı faktör analizi kapsamında özdeğeri birden yüksek olan faktörler dikkate alınarak maddeler üç faktör altında toplanmıştır. Sosyal bilimler alanında yapılan çalışmalarda açıklanan varyansın 0,5 olması yeterli kabul edilmektedir (Yaşlıŏlu, 2017, s. 77). Bu doğrultuda oluşturulan içsel entegrasyon, güven ve performans faktörlerinin açıklanan varyans değeri $(0,58)$ yeterlidir.

Açıklayıcı faktör analizinde sonucunda oluşan yapı bir sonraki adımda doğrulayıcı faktör analizine tabii tutulmuştur. LISREL paket programı aracılığıyla gerçekleştirilen analiz sonuçlarında elde edilen standart, $\mathbf{R}^{2}$ ve T değerleri Tablo $4^{\prime}$ te görülmektedir. Doğrulayıcı faktör analizinde maddelerin faktör yüklerinin 0,5 ve üzerinde bir değere sahip olması beklenmektedir. Analiz sonucunda IC2 maddesi haricinde diğer maddelerin tümü 0,5 değerinin üzerindedir. IC2 maddesi $t$ değerinin $p<0,001$ güven seviyesinde anlamlı olması nedeniyle madde analizden çıkartılmamıştır. Ayrıca tüm maddelerin $t$ değerlerinin $\mathrm{p}<0,001$ güven seviyesinde anlamlı olduğu Tablo 4'ten anlaşılmaktadır.

Yakınsama geçerliliği için ölçüm modelinin elde ettiği açıklanan ortalama varyans (AVE) ve birleşik güvenirlik (CR) değerleri incelenmiştir. Açıklanan ortalama varyansın 0,5'in üzerinde olması istenirken Fornell ve Larcker (1981, s. 46) AVE değerinin 0,5'in altında olduğu durumlarda CR'nin 0,6 'nın üzerinde olmasının yakınsama geçerliliği için yeterli olduğunu ifade etmiştir. İçsel entegrasyonun, güven ve performans ölçeklerinin AVE ve CR değerleri incelendiğinde yapının yakınsama geçerliliğine sahip olduğu görülmektedir. 
Tablo 4: Ölçüm Modeline İlişkin Doğrulayıcı Faktör Analizi Sonuçları

\begin{tabular}{|c|c|c|c|c|c|c|}
\hline Faktörler ve Maddeler & $\begin{array}{l}\text { Standart } \\
\text { Değer }\end{array}$ & $\mathbf{R}^{2}$ Değerleri & $\begin{array}{l}\text { Hata } \\
\text { Varyansı }\end{array}$ & T Değerleri & AVE & CR \\
\hline \multicolumn{7}{|l|}{ İçsel Entegrasyon } \\
\hline IC2 & 0,41 & 0,17 & 0,83 & 7,72 & \multirow{5}{*}{0,37} & \multirow{5}{*}{0,74} \\
\hline IC4 & 0,55 & 0,31 & 0,69 & 10,70 & & \\
\hline IC5 & 0,74 & 0,55 & 0,45 & 15,26 & & \\
\hline IC6 & 0,71 & 0,50 & 0,50 & 14,37 & & \\
\hline IC7 & 0,61 & 0,38 & 0,62 & 12,11 & & \\
\hline \multicolumn{7}{|l|}{ Güven } \\
\hline G1 & 0,68 & 0,46 & 0,54 & 14,32 & \multirow{4}{*}{0,56} & \multirow{4}{*}{0,83} \\
\hline $\mathrm{G} 2$ & 0,79 & 0,63 & 0,37 & 17,74 & & \\
\hline G3 & 0,79 & 0,63 & 0,37 & 17,71 & & \\
\hline G4 & 0,73 & 0,53 & 0,47 & 15,76 & & \\
\hline \multicolumn{7}{|l|}{ Performans } \\
\hline P1 & 0,65 & 0,43 & 0,57 & 13,29 & \multirow{4}{*}{0,47} & \multirow{4}{*}{0,78} \\
\hline P2 & 0,78 & 0,61 & 0,39 & 16,57 & & \\
\hline P3 & 0,64 & 0,41 & 0,59 & 12,89 & & \\
\hline P4 & 0,69 & 0,47 & 0,53 & 14,16 & & \\
\hline
\end{tabular}

\section{Araştırma modelinin ve hipotezlerin test edilmesi}

Araştırma modelinin test edilmesi için değişkenler arasındaki ilişkiler Baron ve Kenny (1986)'nun önerdiği gibi dört aşamada incelenmiştir. İlk aşamada Şekil 2'deki H1a yolu ile gösterilen bağımsız değişken ile bağımlı değişken arasındaki ilişki test edilmiştir. İkinci aşamada ise $\mathrm{H} 2$ yolu ile gösterilen bağımsız değişken ile aracı değişken arasındaki ilişki yapılan analiz ile açıklanmaya çalışılmıştır. H3 yolu ile gösterilen aracı değişken ve bağımlı değişken arasındaki ilişki ise analizin üçüncü aşamasında test edilmiştir. Son aşamada ise H1b yolu ile bağımsız değişkenin aracı değişken üzerinden bağımlı değişken üzerindeki etkisi test edilerek aracılık rolü açılanmaya çalışılmıştır.

İçsel entegrasyonun bağımsız değişken ve tedarik zincirinin süre odaklı performansının bağımlı değişken olduğu regresyon modeli Tablo 5 'de görülmektedir. İçsel entegrasyonun tedarik zincirinin süre odaklı performansını 0,278 katsayısı ile olumlu yönde etkilediği ve bu etkinin $p<0,01$ seviyesinde anlamlı olduğu anlaşılmaktadır. Elde edilen sonuçlar ile "H1a: İçsel entegrasyonun tedarik zincirinin süre odaklı performansı üzerinde anlamlı ve olumlu yönde bir etkisi bulunmaktadır" hipotezi kabul edilmektedir. Tedarik zincirinin süre odaklı performansındaki değişimin yaklaşık \%11'i içsel entegrasyon ile açılanmaktadır.

Tablo 5: İçsel Entegrasyonun Tedarik Zincirinin Süre Odaklı Performansı Üzerindeki Etkisinin Araştırılması (H1a)

\begin{tabular}{|l|l|l|l|l|l|l|}
\hline $\begin{array}{l}\text { Bağımı̆ı } \\
\text { Değişken }\end{array}$ & $\begin{array}{l}\text { Bağımsız } \\
\text { Değişken }\end{array}$ & $\mathbf{F}$ & Coeff & $\mathbf{T}$ & $\mathbf{p}$ & $\boldsymbol{R}^{\mathbf{2}}$ \\
\hline $\begin{array}{l}\text { TZ'nin Süre } \\
\text { Odaklı } \\
\text { Performansı }\end{array}$ & $\begin{array}{l}\text { İçsel } \\
\text { Entegrasyon }\end{array}$ & 51,956 & 0,278 & 7,208 &, 000 & 0,115 \\
\hline
\end{tabular}

İçsel entegrasyonun bağımsız değişken ve güvenin bağımlı değişken olduğu regresyon modeli Tablo 6'da görülmektedir. İçsel entegrasyonun güveni 0,402 katsayısı ile olumlu yönde etkilediği ve bu etkinin $\mathrm{p}<0,01$ seviyesinde anlamlı olduğu anlaşılmaktadır. Elde edilen sonuçlar ile "H2: İçsel entegrasyonun güven faktörü üzerinde anlamlı ve olumlu yönde bir etkisi bulunmaktadır" hipotezi kabul edilmektedir. Güvendeki değişimin yaklaşık \%18'i içsel entegrasyon ile açıklanmaktadır. 
Tablo 6: İçsel Entegrasyonun Güven Üzerindeki Etkisinin Araştırılması (H2)

\begin{tabular}{|l|l|l|l|l|l|l|}
\hline $\begin{array}{l}\text { Bağı̆ı̆ı } \\
\text { Değişken }\end{array}$ & $\begin{array}{l}\text { Bağımsız } \\
\text { Değişken }\end{array}$ & $\mathbf{F}$ & Coeff & $\mathbf{T}$ & $\mathbf{p}$ & $\boldsymbol{R}^{\mathbf{2}}$ \\
\hline Güven & $\begin{array}{l}\text { İçsel } \\
\text { Entegrasyon }\end{array}$ & 90,443 & 0,402 & 9,510 &, 000 & 0,184 \\
\hline
\end{tabular}

Güvenin bağımsız değişken ve tedarik zincirinin süre odaklı performansının bağımlı değişken olduğu regresyon modeli Tablo 7'de görülmektedir. Güvenin tedarik zincirinin süre odaklı performansını 0,481 katsayısı ile olumlu yönde etkilediği ve bu etkinin $p<0,01$ seviyesinde anlamlı olduğu anlaşılmaktadır. Elde edilen sonuçlar ile "H3: Güven faktörünün, tedarik zincirinin süre odaklı performansı üzerinde anlamlı ve olumlu yönde bir etkisi bulunmaktadır" hipotezi kabul edilmektedir. Tedarik zincirinin süre odaklı performansındaki değişimin yaklaşık \%23’ü güven ile açıklanmaktadır.

Tablo 7: Güvenin Tedarik Zincirinin Süre Odaklı Performansı Üzerindeki Etkisinin Araştırılması (H3)

\begin{tabular}{|l|l|l|l|l|l|l|}
\hline $\begin{array}{l}\text { Bağı̆ııı } \\
\text { Değişken }\end{array}$ & $\begin{array}{l}\text { Bağımsız } \\
\text { Değişken }\end{array}$ & $\mathbf{F}$ & Coeff & $\mathbf{T}$ & $\mathbf{p}$ & $\boldsymbol{R}^{\mathbf{2}}$ \\
\hline $\begin{array}{l}\text { TZ'nin Süre } \\
\begin{array}{l}\text { Odaklı } \\
\text { Performansı }\end{array}\end{array}$ & Güven & 120,138 & 0,481 & 10,961 &, 000 & 0,231 \\
\hline
\end{tabular}

Tablo 5, Tablo 6 ve Tablo 7'nin sonuçları dikkate alındığında aracılık etkisinin test edilmesi için tüm koşulların sağlandığı ifade edilebilir. Tablo 8 incelendiğinde içsel entegrasyonun tedarik zincirinin süre odaklı performansı üzerindeki etkisinin 0,278'den (Tablo 5) 0,133'e (Tablo 8) düştüğü görülmektedir. Elde edilen sonuçlara göre güven boyutunun kısmı aracılık rolü oynadı̆̆1 anlaşılmaktadir.

Tablo 8: İçsel Entegrasyonun Tedarik Zincirinin Süre Odaklı Performansı Üzerindeki Etkisinde Güvenin Aracılık Etkisinin Araştırılması (H1b)

\begin{tabular}{|l|l|l|l|l|l|l|}
\hline $\begin{array}{l}\text { Bağımıı } \\
\text { Değişken }\end{array}$ & $\begin{array}{l}\text { Bağımsız } \\
\text { Değişken }\end{array}$ & $\mathbf{F}$ & Coeff & $\mathbf{T}$ & $\mathbf{p}$ & $\boldsymbol{R}^{\mathbf{2}}$ \\
\hline $\begin{array}{l}\text { TZ'nin Süre } \\
\text { Odak1ı } \\
\text { Performansı }\end{array}$ & $\begin{array}{l}\text { İçsel } \\
\text { Entegrasyon }\end{array}$ & 67,409 & 0,133 & 3,394 &, 000 & 0,252 \\
\hline $\begin{array}{l}\text { TZ'nin Süre } \\
\text { Odaklı } \\
\text { Performansı }\end{array}$ & Güven & 67,409 & 0,359 & 8,570 &, 000 & 0,252 \\
\hline
\end{tabular}

Aracılık etkisinin test edilmesinde kullanılan Bootstrap analiz sonuçları Tablo 9'da görülmektedir. CI değerlerinin sıfırı içermemesi ve p değerinin 0,05'den küçük olması hipotezlerin doğrulandığını ifade etmektedir (Serinikli, 2020). Elde edilen sonuçlar incelendiğinde doğrudan etkinin araştırıldığı H1a ve H2 ile dolaylı etkinin araştırıldığ1 H1b hipotezlerinin doğrulandığı görülmektedir.

Tablo 9: Bootstrap Sonuçları

\begin{tabular}{|l|l|l|l|l|}
\hline Hipotezler & Yol & SH & LLCI & ULCI \\
\hline H1a & IE $\rightarrow_{\text {TZP }}$ & 0,0306 & 0,0911 & 0,2097 \\
\hline H2 & G $\rightarrow_{\text {TZP }}$ & 0,0460 & 0,1692 & 0,3495 \\
\hline H1b & IE $\rightarrow_{\text {G }} \rightarrow_{\text {TZP }}$ & 0,0328 & 0,1157 & 0,2453 \\
\hline
\end{tabular}

Aracılık etkisinin analizinde kullanılan diğer bir yöntem ise sobel testidir. Bağımsız değişken ile aracı değişken arasındaki ilişkide standardize edilmemiş regresyon katsayısı $(a)$ ve standart hata $\left(s_{a}\right)$, bağımsız değişken ve aracı değişkenin bağımlı değişken üzerindeki etkisini açıklamak için kurulan ilişkide standardize edilmemiş regresyon katsayısı $(b)$ ve standart hata $\left(s_{b}\right)$ sobel test istatistiğinin hesaplanmasında kullanılmaktadır. Sobel test istatistiğinin <.95 güven seviyesinde 1.96 'dan büyük olması beklenmektedir. Tablo 10'da görülen sobel istatistiği değeri <.95 güven seviyesindeki referans değerinden büyük ve $\mathrm{p}$ değeri <.05 ile anlamlıdır. Elde edilen sonuçlarla H1b hipotezi sobel testi sonuçlarına göre de doğrulanmıştır. 
Tablo 10: Sobel İstatistiği Sonuçları

\begin{tabular}{|l|l|l|}
\hline Sobel Test İstatistiği & Standart Hata & P Değeri \\
\hline 6.689 & 0.021 & 0 \\
\hline
\end{tabular}

İşletme içindeki lojistik, pazarlama ve üretim fonksiyonları arasındaki içsel entegrasyonun tedarik zinciri performansına etkisi farklı çalışmalarda (Won Lee, Kwon ve Severance, 2007; Flynn ve diğerleri, 2010) tespit edilmiştir. Yapılan çalışma kapsamında içsel entegrasyonun tedarik zincirinin süre odaklı performansına etkisi ilk defa incelenmiş olup bu etki doğrulanmıştır. Tedarik zinciri dışsal entegrasyon öğeleri arasındaki güven unsurunun tedarik zinciri performansına etkisi yine daha önceki çalışmalarda (Cai, Jun ve Yang, 2010; Ramirez, Roman, Ramos ve Patrucco, 2020) ele alınmasına karşın içsel entegrasyon öğeleri arasındaki güven unsurunun tedarik zinciri performansına etkisi bu çalışmada ilk defa incelenmiş olup bu doğrultuda literatürdeki boşluk doldurulmaya çalışılmıştır.

\section{Sonuç}

Küreselleşmenin etkisiyle işletmeler, farklı iş modelleri geliştirerek uzak coğrafyalardan hammadde ya da yarı mamül tedarik etmeye, pazar bulmaya, sürekli ve hızlı bir şekilde yeni ürün geliştirmeye zorlanmaktadır. İşletmelerin sınırlı kaynakları ile rekabet avantajı kazanması günümüz şartlarında imkânsız hale gelmiştir. Rekabetin işletme sınırları dışına çıkarak tedarik zincirleri düzeyine taşındığı ise artık bilinen bir gerçektir. Tedarik zincirlerinin artan önemi konunun hem teorisyenler hem de pratisyenler tarafından ilgi ile takip edilmesini sağlamaktadır. Son yıllarda tedarik zincirinin içsel ve dışsal entegrasyonunun maliyet, yeni ürün geliştirme, kalite üzerine etkisi olduğunu ifade eden çalışmalar yapılmıştır. Bu çalışmada ise içsel entegrasyonun tedarik zincirinin süre odaklı performansı üzerindeki etkisinde güven boyutunun aracılık rolüne sahip olup olmadığı araştırılmıştır. İşletmenin departmanları arasındaki koordinasyonu/iş birliğini ifade etmekte olan içsel entegrasyon çalışmada; lojistik, pazarlama ve üretim departmanları arasında kurulan entegrasyon özelinde değerlendirilmektedir. İçsel entegrasyon işletme içerisinde yer alan departmanların ayrık faaliyetlerinin senkronize edilmesini sağlamaktadır. Bu sayede işletmenin tüm departmanlarının aynı amaç doğrultusunda faaliyetlerine devam etmesi sağlanabilir. Etkin bir içsel entegrasyon işletme kaynaklarının israfını engelleyerek maliyet, kalite ve hız konusunda rekabet avantajı kazandırabilir. Bu doğrultuda çalışmada içsel entegrasyonun tedarik zincirinin süre odaklı performansını olumlu yönde etkileyeceğini ifade eden hipotez test edilmiş ve doğrulanmıştır. Bulunan sonuç içsel entegrasyonun tedarik zinciri performansına olumlu yönde etkilerinin bulunduğu çalışmalarla (Abdallah ve diğerleri (2014); Shee ve diğerleri (2018); Peng ve diğerleri (2020)) uyum içerisindedir.

İşletme içinde içsel entegrasyonun oluşturulması, farklı departmanların ortak amaç doğrultusunda faaliyetlerini diğer departmanlarla koordine etmesini gerektirmektedir. Departmanlar arası etkileşim ve koordinasyon ile işletme içerisinde yer alan her birimin diğer birimlerle bir rekabet içerisinde olmadığı ve tüm süreç boyunca değer yaratmak amaçlanmaktadır. Böylece işletme fonksiyonları arasında tesis edilen entegrasyon, çalışanların ve departmanların birbirlerine güvenmelerini sağlamaktadır. Bu doğrultuda oluşturulan içsel entegrasyonun güven boyutunu olumlu yönde etkilerinin bulunduğu hipotezi analiz edilmiş ve doğrulanmıştır. Söz konusu analiz sonucu, bu alanda yapılan çalışmalar ile uyumludur.

Nasıl ki ekonomik değerin karşılığı olarak kabul edilen para birimleri dahi güven üzerinde yükseliyorsa tedarik zinciri performansı da paydaşlar arasındaki güven unsuru ile artmaktadır. Güven faktörü sosyal ilişkilerde olduğu kadar iş ilişkilerinde de önemli yere sahiptir. Son yıllarda tedarik zinciri üyeleri arasındaki güven eksikliğinin yaratmış olduğu negatif etkileri en aza indirebilmek için ademi merkeziyetçi bir yapıya sahip olan blok zincir teknolojisi tedarik zincirlerinde kullanılmaya başlanmıştır (Koç, 2020). Tedarik zinciri içsel entegrasyonunun kurulmasında departmanlar arasındaki güvenin tesis edilmesi faaliyetlerin bürokratik zaman kaybına uğramadan gerçekleştirilmesine imkân tanıyacaktır. Bu bilgiler 1şı̆̆ında oluşturulan güven boyutunun tedarik zincirinin süre odaklı performansı üzerinde olumlu etkilerinin bulunduğu hipotezi test edilmiş ve doğrulanmıştır.

Bu çalışmadan hareketle hemen hemen her sektörde rekabet yoğunluğunun arttığ günümüzde işletme yöneticilerinin departmanlar arasında içsel entegrasyonu tesis ettikleri takdirde tedarik zincirlerinin süre odaklı performansının artırılabileceği ifade edilebilir. Özellikle pandemi koşulları da dikkate alındığında işletmeler bu sayede müşteri siparişlerine daha hızlı cevap verebilecektir. Çalışma zaman ve maliyet kıstı nedeniyle yalnızca Türkiye içerisinde gerçekleştirilmiştir. Gelecekte yapılacak çalışmalarda farklı bağımsız ve aracı değişkenlerle tedarik zincirinin süre odaklı performansına etki 
eden unsurlar araştırılabilir. Aynı bağımsız ve aracı değişkenin farklı bağımlı değişken üzerindeki etkisi de araştırılarak literatüre katkı sağlanabilir. Ayrıca mevcut araştırma modeline farklı aracı ya da düzenleyici değişkenler de eklenerek yeni bir model oluşturularak test edilebilir. Çalışma imalat sektörü ana evreni üzerinden gerçekleştirildiğinden farklı araştırmalar hizmet sektörü üzerinde de gerçekleştirilebilir.

\section{Hakem Değerlendirmesi / Peer-review:}

Dış bağımsız

Externally peer-reviewed

\section{Çıkar Çatışması / Conflict of interests:}

Yazarlar çıkar çatışması bildirmemiştir.

The authors have no conflict of interest to declare.

\section{Finansal Destek / Grant Support:}

Yazarlar bu çalışma için finansal destek almadığını beyan etmiştir.

The authors declared that this study has received no financial support.

\section{Etik Kurul Onay1 / Ethics Committee Approval:}

Bu çalışma için etik kurul onayı, Hacettepe Üniversitesi Etik Kurulundan 22/11/2017 tarihli 35853172/433-4040 sayılı karar ile alınmıştır.

Ethics committee approval was received for this study from the Ethics Committee of Hacettepe University on 22/11/2017 and 35853172/433-4040 document number.

\section{Yazar Katkıları / Author Contributions:}

Fikir/Kavram/Tasarım - Idea/Concept/ Design: H.Ç., Z.S. Veri Toplama ve/veya İşleme - Data Collection and/or Processing: Z.S. Analiz ve/veya Yorum - Analysis and/or Interpretation: Z.S., E.K. Kaynak Taraması - Literature Review: H.Ç., Z.S. Makalenin Yazımı - Writing the Article: H.Ç., Z.S., E.K. Eleştirel İnceleme - Critical Review: Z.S., E.K. Onay - Approval: H.Ç., Z.S., E.K.

\section{Kaynakça / References}

Abdallah, A. B., Obeidat, B. Y. ve Aqqad N. O. (2014). The impact of supply chain management practices on supply chain performance in Jordan: The moderating effect of competitive intensity. International Business Research, 7(3), 13-27.

Acar, A. Z. ve Uzunlar B. (2014). The effects of process development and information technology on time-based supply chain performance. Social and Behavioral Sciences, 150(1), 744-753.

Alfalla-Luque, R., Medina-Lopez, C. ve Dey P. K. (2013). Supply chain integration framework using literature review. Production Planning \& Control, 24(8-9), 800-817.

Alkan, F. ve Erdem R. (2020). Mutluluk ile geçici yeti yitimi arasındaki ilişkinin incelenmesi. Sağlık ve Toplum, 20(3), 69-79.

Ballou, R. H. (2004). Business logistics/supply chain management, New Jersey: Pearson Education.

Baron, R. M. ve Kenny D. A. (1986). The moderator-mediator variable distinction in social psychological research: Conceptual, strategic and statistical considerations. Journal of Personality and Social Psychology, 51, 1173-1182.

Bower, J. L. ve Hout T. M. (1988). Fast-cycle capability for competitive power. Harward Business Review, 66(6), 110-118. 
Brewer, P. C. ve Speh T. W. (2000). Using the balanced scorecard to measure supply chain performance. Journal of Business Logistics, 21(1), 75-93.

Bunduchi, R. (2013). Trust, partner selection and innovation outcome in collaborative new product development. Production Planning \& Control, 24 (2/3), 145-157.

Burgess, K., Singh, P. J. ve Koroglu R. (2006). Supply chain management: A structured literature review and implications for future research. International Journal of Operations \& Production Management, 26(7), 703-729.

Cai, S., Jun, M. ve Yang Z. (2010). Implementing supply chain information integration in China: The role of institutional forces and trust. Journal of Operations Management, 28(3), 257-268.

Can, R. (2014). Türk edebiyatı dersine yönelik tutum ölçeğinin geliştirilmesi. Uluslararası Avrasya Sosyal Bilimler Dergisi, 5(17), 111-127.

Cengiz, E. ve Aksoy H. (2017). Tedarik zinciri elemanları arasında güven ilişkisi, etik kurallar ve bilgi paylaşımının tedarik zinciri performansı üzerine etkisi. C. Ü. İktisadi ve İdari Bilimler Dergisi, 18(2), 1-22.

Chen, I. J. ve Paulraj A. (2004). Understanding supply chain management: critical research and a theoretical framework. International Journal of Production Research, 42 (1), 131-163.

Chen, H., Daugherty, P. J. ve Landry T. D. (2009). Supply chain process integration: A theoretical framework. Journal of Business Logistics, 30(2), 27-46.

Chen, H., Mattioda, D. D. ve Daugherty P. J. (2007). Firm-wide integration and firm performance. The International Journal of Logistics Management, 18(1), 5-21.

Cheng, Y., Farooq, S. ve Jajja M. S. S. (2020). Does plant role moderate relationship between internal manufacturing network integration, external supply chain integration, operational performance in manufacturing network. Journal of Manufacturing Technology Management, 18(1), 5-21.

Daugherty, P. J. ve Pittman P. H. (1995). Utilization of time-based strategies: Creating distribution flexibility/responsiveness. International Journal of Operations \& Production Management, 15(2), 54-60.

Daugherty, P. J., Chen, H., Mattioda, D. D. ve Grawe S. J. (2009). Marketing/logistics relationships: Influence on capabilities and performance. Journal of Business Logistics, 30(1), 1-18.

Droge, C., Jayaram, J. ve Vickery S. K. (2004). The effects of internal versus external integration practices on time-based performance and overall performance. Journal of Operations Management, 22, 557-573.

Ellinger, A. E. (2000). Improving marketing/logistics cross-functional collaboration in the supply chain. Industrial Marketing Management, 29(1), 85-96.

Ellinger, A. E., Keller, S. B. ve Hansen J. D. (2006). Bridging the divide between logistics and marketing: Facilitating collaborative behaviour. Journal of Business Logistics, 27(2), 1-28.

Estampe, D., Lamouri, S., Paris, J. L. ve Brahim-Djelloul S. (2013). A framework for analysing supply chain performance evaluation models. International Journal of Production Economics, 142(2), 247-258.

Fawcett, S. E. ve Closs D. J. (1993). Coordinated global manufacturing, the logistics/manufacturing interaction, and firm performance. Journal of Business Logistics, 14(1), 1-25.

Flynn, B. B., Huo, B. ve Zhao X. (2010). The impact of supply chain integration on performance: A contingency and configuration approach. Journal of Operations Management, 28(1), 58-71.

Fornell, C. ve Larcker D. F. (1981). Evaluating structural equation models with unobservable variables and measurement error. Journal of Marketing Research, 18(1), 39-50.

Freijele, I., Calle, A. ve Ugarte J. V. (2020). Role of supply chain integration in the product innovation capability of servitized manufacturing companies. Technovation, 1-14.

Frankel, R., Bolumole, Y. A., Eltantawy, R. A., Paulraj, A. ve Gundlach G. T. (2008) The domain and scope of SCM's foundational disciplines - insights and issues to advance research. Journal of Business Logistics, 29(1), 1-30. 
Frohlich, M. T. ve Westbrook R. (2001). Arcs of integration: An international study of supply chain strategies. Journal of Operations Management, 19(2), 185-200.

Garcia, N., Sanzo, M. J. ve Trespalacios J. A. (2008). New product internal performance and market performance: Evidence from Spanish firms regarding the role of trust, interfunctional integration, and innovation type. Technovation, 28 (11), 713-725.

Germain, R. ve Iyer K. N. S. (2006). The interaction of internal and downstream integration and its association with performance. International Journal of Business Logistics, 27(2), 29-52.

Gimenez, C. ve Ventura E. (2005). Logistics-production, logistics-marketing and external integration. International Journal of Operations \& Production Management, 25(1), 20-38.

Gomes, J. F., de Weerd-Nederhof, P., Pearson, A. ve Cunha M. (2003). Is more always better? An exploration of the differential effects of functional integration on performance in new product development. Technovation, 23(3), 185-191.

Gunasekaran, A., Patel, C. ve Tirtiroglu E. (2001). Performance measures and metrics in a supply chain environment. International Journal of Operations \& Production Management, 21(1/2), 71-87.

Holmberg, S. (2000). A systems perspective on supply chain measurements. International Journal of Physical Distribution and Logistics Management, 30(10), 847-868.

Jacobs, M. A., Yu, W. ve Chavez R. (2016). The effect of internal communication and employee satisfaction on supply chain integration. International Journal of Production Economics, 171, 60-70.

Jayaram, J., Vickery, S. A. ve Droge C. (2000). The effects of information system infrastructure and process improvements on supply chain time performance. International Journal of Physical Distribution and Logistics Management, 30(3/4), 314-330.

Jayaram, J. ve $\mathrm{Xu} \mathrm{K.} \mathrm{(2013).} \mathrm{The} \mathrm{relative} \mathrm{influence} \mathrm{of} \mathrm{external} \mathrm{versus} \mathrm{internal} \mathrm{integration} \mathrm{on} \mathrm{plant}$ performance in China. International Journal of Production Economics, 146(1), 59-69.

Jeffries, F. L. ve Reed R. (2000). Trust and adaptation in relational contracting. The Academy of Management Review, 25 (4), 873-882.

Kahn, K. B. ve Mentzer J. B. (1996). Logistics and interdepartmental integration. International Journal of Physical Distribution and Logistics Management, 26(8), 6-14.

Kahn, K. B. ve McDonough E. F. (1997). Marketing's integration with R@D and manufacturing: A cross-regional analysis. Journal of International Marketing, 5(1), 51-76.

Kahn, K. B. ve Mentzer J. B. (1998). Marketing's integration with other departments. Journal of Business Research, 42(1), 53-62.

Kanda, A. A. ve Deshmukh S. G. (2008). Supply chain coordination: Perspectives, empirical studies and research directions. International Journal of Production Economics, 115(1), 316-335.

Kelle, P. ve Akbulut A. (2005). The role of ERP tools in supply chain information sharing, cooperation, and cost optimization. International Journal of Production Economics, 93, 41-52.

Koç, E. (2020). Tedarik zinciri izlenebilirliği ve sürdürülebilirliğinde yeni paradigma: Blokzincir. Bingöl Üniversitesi Sosyal Bilimler Enstitüsü Dergisi, 20, 417-437.

Li, W. Y., Chow, P. S., Choi, T. M. ve Chan H. L. (2016). Supplier integration, green sustainability programs, and financial performance of fashion enterprises under global financial crisis. Journal of Cleaner Production, 135, 57-70.

Liu, Z. ve Jayaram V. (2019). Exploring the effect of internaland external integration on the performance of professional service outsourcing. Journal of Global Operations and Strategic Sourcing, 12(3), 410-428.

Lummus, R. R. ve Vokurka R. J. (1999). Defining supply chain management: a historical perspective and practical guidelines. Industrial Management @ Data Systems, 99(1), 11-17.

Maiga, A. S., Nilsson, A. ve Ax C. (2015). Relationships between internal and external information systems integration, cost and quality performance, and firm profitability. International Journal of Production Economics, 169, 422-434. 
Makepeace, D., Tatham, P. ve Wu Y. (2017). Internal integration in humanitarian supply chain management: perspectives at the logistics-programmes interface. Journal of Humanitarian Logistics and Supply Chain Management, 7(1), 26-56.

McAllister, D. J. (1995). Affect- and cognition- based trust as foundations for interpersonal cooperation in organizations. Academy of Management Journal, 38 (1), 24-59.

Mentzer, J. T., Dewitt, W., Keebler, J. S., Min, S., Nix, N. W., Smith, C. D. ve Zacharia Z. G. (2001). Defining supply chain management. Journal of Business Logistics, 22(2), 1-26.

Moorman, C., Zaltman, G. ve Deshpande R. (1992). Relationships between providers and users of market research: the dynamics of trust within and between organizations. Journal of Marketing Research, 29(August), 314-328.

Montoya-Weiss, M. M., Massey, A. P. ve Song X. M. (2001). Getting it together: Temporal coordination and conflict management in global virtual teams. Academy of Management Journal 44, 1251-1262.

Morash, E. A., Dröge, E. ve Vickery S. (1996). Boundary-spanning interfaces between logistics, production, marketing and new product development. International Journal of Physical Distribution and Logistics Management, 27(5/6), 350-369.

Morgan, R. M. ve Hunt S. D. (1994). The commitment-trust theory of relationship marketing. Journal of Marketing, 58(July), 20-38.

Narasimhan, R. ve Kim S. W. (2001). Information system utilization strategy for supply chain integration. Journal of Business Logistics, 22(2), 51-75.

O'Leary-Kelly, S. W. ve Flores B. E. (2002). The integration of manufacturing and marketing/sales decisions: Impact on organizational performance. Journal of Operations Management, 20(3), 221240.

Pagell, M. (2004). Understanding the factors that enable and inhibit the integration of operations, purchasing and logistics. Journal of Operations Management, 22(5), 459-487.

Paiva, E. L. (2010). Manufacturing and marketing integration from a cumulative capabilities perspective. International Journal of Production Economics, 126(2), 379-386.

Peng, H., Shen, N., Liao, H. ve Wang Q. (2020). Multiple network embedding, green knowledge integration and green supply chain performance: Investigation based on agglomeration scenario. Journal of Cleaner Production, 259, 1-13.

Perçin, S. (2005). Tedarik zincirinin zamana dayalı performansının ölçülmesi: Türk otomotiv yan sanayi uygulaması. Ankara Üniversitesi Sosyal Bilimler Fakültesi Dergisi, 60(3), 173-194.

Phadnis, S. S. ve Fine C. H. (2017). End-to-end supply chain strategies: A parametric study of the apparel industry. Production and Operations Management, 26(12), 2305-2322.

Ramirez, M. J., Roman, I. E., Ramos, E. ve Patrucco A. S. (2020). The value of supply chain integration in the Latin American agri-food industry: Trust, commitment and performance outcomes. The International Journal of Logistics Management, 32(1), 284-304.

Rimiene, K. ve Bernatoynte D. (2013). Supply Chain management trends in the context of change. Economics and Management, 18(3), 596-606.

Ross, D. F. (2011). Introduction to supply chain management technologies, Boca Raton: Taylor and Francis Group.

Schramm-Klein, H. ve Morschett D. (2006). The relationship between marketing performance, logistics performance and company performance for retail companies. Int. Rev. Of Retail, Distribution and Consumer Research, 16(2), 277-296.

Shah, N. ve Soomro B. A. (2020). Internal green integration and environmental performance: The predictive power of proactive environmental strategy, greening the supplier, and environmental collaboration with the supplier. Business Strategy and Environment, 30(2), 1333-1344.

Serinikli, N. (2020). Sağlık çalışanlarında iş özerkliği ve iş performansı arasındaki ilişkide örgütsel sinizm ve yaşam tatmini seri çoklu arabuluculuğu. İşletme Araştırmaları Dergisi, 12(2), 1693-1711.

Shee, H., Miah, S. J., Fairfield, L. ve Pujawan N. (2018). The impact of cloud-enabled process integration on supply chain. Supply Chain Management, 23(6), 500-517. 
Springinklee, M. ve Wallenburg C. M. (2012). Improving distribution service performance through effective production and logistics integration. Journal of Business Logistics, 33(4), 309-323.

Stank, T. P., Daugherty, P. J. ve Ellinger A. E. (1999). Marketing/logistics integration and firm performance. The International Journal of Logistics Management, 10(1), 11-24.

Stock, G. N., Greis, N. P. ve Kasarda J. P. (1998). Logistics, strategy and structure: A conceptual framework. International Journal of Operations \& Production Management, 18(1), 37-52.

Stock, G. N., Greis, N. P. ve Kasarda J. P. (2000). Enterprise logistics and supply chain structure: The role of fit. Journal of Operations Management, 18(5), 531-547.

Swink, M., Narasimhan, R. ve Wang C. (2007). Managing beyond the factory walls: Effects of four types of strategic integration on manufacturing plant performance. Journal of Operations Management, 25 (1), 148-164.

Şengün, A. E. (2007). Alıcı-tedarikçi ilişkilerinde güven ve güvensizliğin mübadele performansı üzerine etkileri: Ankara mobilyacılar sitesi örneği. Yönetim Araştırmaları Dergisi, 7(1-2), 5-38.

Tan, K. C. (2001). A framework of supply chain management literature. European Journal of Purchasing \& Supply Management, 7(1), 39-48.

Tarifa-Fernandez, J. ve Burgos-Jimenez J. D. (2017). Supply chain integration and performance relationship: A moderating effects review. The International Journal of Logistics Management, 28(4), 1243-1271.

Tersine, R. J. ve Hummingbird E. A. (1995). Lead-time reduction: The search for competitive advantage. International Journal of Operations \& Production Management, 15(2), 8-18.

Turkulainen, V. ve Ketokivi M. (2012). Cross-functional integration and performance: What are the real benefits?. International Journal of Operations \& Production Management, 32(4), 447-467.

Verma, R., Thompson, G. M., Moore, W. L. ve Louviere J. J. (2001). Effective design of product/services: An approach based on integration of marketing and operations management decisions. Decision Sciences, 31(1), 165-193.

Won Lee, C., Kwon, I. G. ve Severance, D. (2007). Relationship between supply chain performance and degree of linkage among supplier, internal integration, and customer. Supply Chain Management, 12(6), 444-452.

Wong, C. W. Y., Wong, C. Y. ve Boon-itt S. (2013). The combined effects of internal and external supply chain integration on product innovation. International Journal of Production Economics, 146(2), 566-574.

Wu, I. L., Chuang, C. H. ve Hsu C. H. (2014). Information sharing and collaborative behaviors in enabling supply chain performance: A social exchange perspective. International Journal of Production Economics, 148(1), 122-132.

Yaşlıŏglu, M. M. (2017). Sosyal bilimlerde faktör analizi ve geçerlilik: Keşfedici ve doğrulayıcı faktör analizlerinin kullanılması. İstanbul Üniversitesi İşletme Fakültesi Dergisi, 46, 74-85.

Ye, F. ve Wang Z. (2013). Effects of information technology alignment and information sharing on supply chain operational performance. Computers \& Industrial Engineering, 65(3), 370-377.

Zaheer, A., McEvily B. ve Perrone V. (1998). Does trust matter? Exploring the effects of interorganizational and interpersonal trust on performance. Organization Science, 9 (2), 141-159.

Zhao, X., Huo, B., Selen, W. ve Yeung J. H. Y. (2011). The impact of internal integration and relationship commitment on external integration. Journal of Operations Management, 29 (1/2), 17-32. 